\title{
Syndrome de Wellens
}

\section{Wellens syndrome}

\section{O. Peyrony $\cdot$ A. Elezi $\cdot$ P. Taboulet}

Reçu le 31 mai 2013 ; accepté le 25 juin 2013

(C) SFMU et Springer-Verlag France 2013

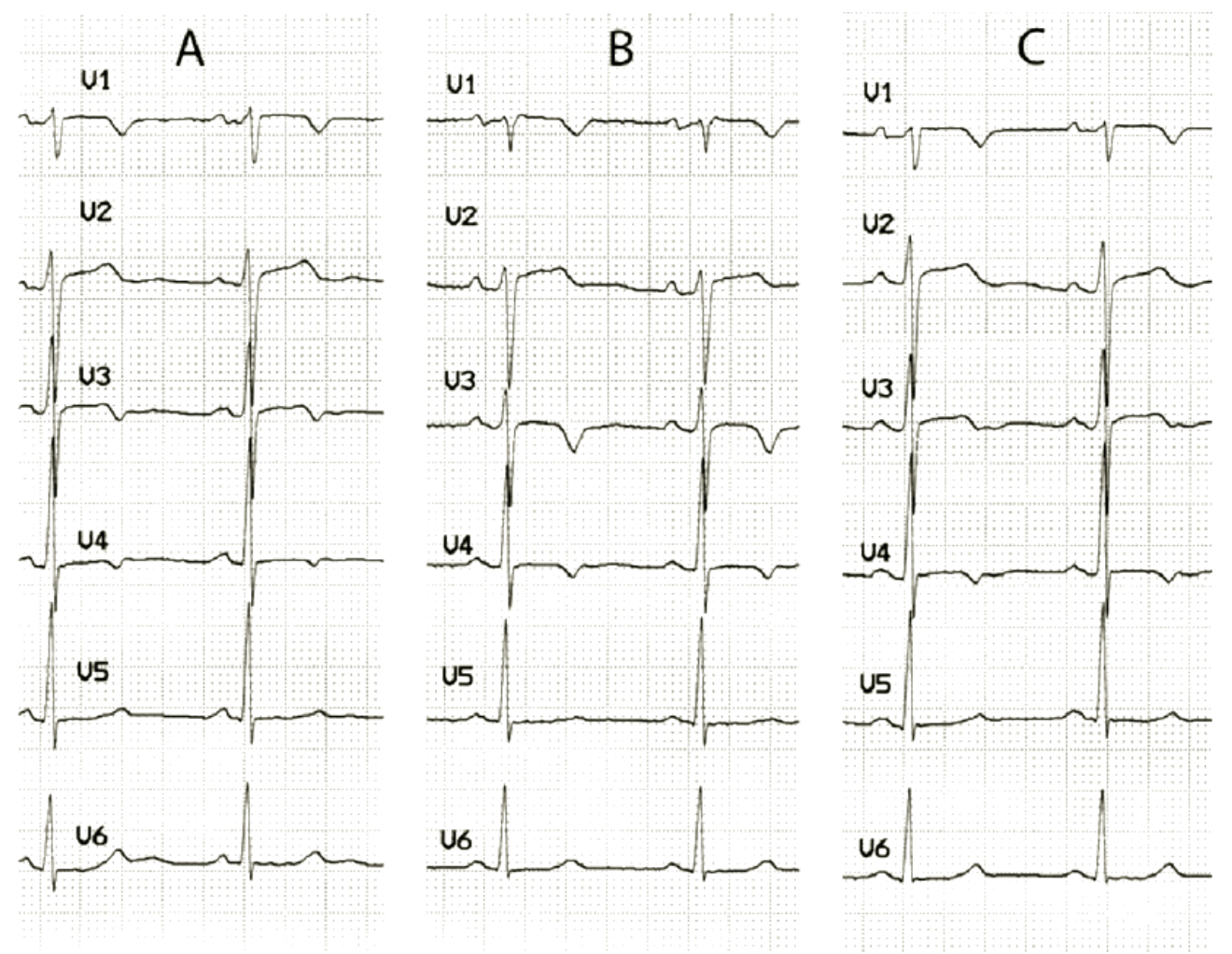

Fig. 1 ECG évocateur d'un syndrome de Wellens

Une patiente de 43 ans consulte aux urgences pour des douleurs épigastriques irradiant vers l'épaule, intermittentes, quotidiennes, majorées à l'effort, depuis six mois. L'examen clinique est sans particularité. L'ECG initial montre une onde T bifide en V3-V4 (Fig. 1A) évoquant un syndrome de Wellens. Le syndrome de Wellens se caractérise par une sténose sans occlusion de l'artère interventriculaire antérieure (IVA). Les patients sont souvent asymptomatiques lors de leur prise en charge. L'ECG montre classiquement des ondes T bifides en V2-V4 (type A)

O. Peyrony $(\bowtie) \cdot$ A. Elezi $\cdot$ P. Taboulet

Service des urgences, hôpital Saint-Louis, Assistance publique - hôpitaux de Paris,

1, avenue Claude Vellefaux, F-75010 Paris, France

e-mail : olivier.peyrony@sls.aphp.fr sans onde Q [1]. L'évolution se fait en général vers une revascularisation avec l'apparition d'ondes $\mathrm{T}$ négatives (type B). Cette entité, si elle passe inaperçue, est à haut risque d'infarctus antérieur en cas d'occlusion de l'IVA. Ici, il s'agit d'une forme atypique puisque l'inversion finale de l'onde T n'est pas présente en V2. Néanmoins, devant la négativation fugace des ondes T sur les ECG suivants (Fig. 1B, C), une coronarographie est réalisée qui montre une sténose serrée de l'IVA moyenne.

\section{Référence}

1. de Zwaan C, Bar FW, Wellens HJJ (1982) Characteristic electrocardiographic pattern indicating a critical stenosis high in left anterior descending coronary artery in patients admitted because of impending myocardial infarction. Am Heart J 103:730-6 